\title{
In-Between Windowscapes: A Curator's Perspective on Collaboration as Artistic Activation in Public Spaces
}

\author{
Wilson Yeung Chun Wai \\ RMIT University, School of Architecture \& Urban Design, Australia \\ chunwaiyeung@gmail.com
}

\begin{abstract}
This paper emphasizes that curatorial practice and site-specific art are essential aspects of the transition from artistic collaboration to collaborative curatorial practice and discovers the new potential of 'curator as collaborator' practice to cultivate communitybased, collaborative and engaging cultural projects in public spaces. By examining the curatorial residency of my participation in Public Space 50 at RMIT University, Melbourne, Australia in 2017, this-portfolio investigates how I, as a curator, explore art curation locations and methods to enable students to actively work collaboratively to plan, facilitate and produce public art projects. It asks how to turn public spaces into laboratories; how can student artists work together in public space; how to empower a creative student community through artistic collaboration and how artistic activation can be developed among creative participators of different cultures and backgrounds?
\end{abstract}

Keywords: Public Space 50, artistic activation, curator as collaborator, windowscapes, curatorial in-between practice

To cite this article:

Yeung, W. (2020) In-Between Windowscapes: A Curator's Perspective on Collaboration as Artistic Activation in Public Spaces, The Journal of Public Space, 5(4), 259-272, DOI 10.3289|/jps.v5i4.1418

This article has been reviewed by the Editors and accepted for publication in The Journal of Public Space.

(C) (-) This work is licensed under a Creative Commons Attribution - Non Commercial 4.0 International License https://creativecommons.org/licenses/by-nc/4.0/ 
Public Space 50 (PS50) is a street viewed exhibition space in the RMIT Building 50 supported by RMIT's Master of Arts (Art in Public Space) program. It takes the form of public window spaces, the street space in front and the lane running down the side of Building 50, and a projection space on a wall opposite to the building. PS50 is viewable 24 hours a day, seven days a week. It creates a significant experience for RMIT student artists to present works to a passing audience and provides them with an opportunity to develop new practices.

From August to November 2017, I participated in the PS50 curatorial residency program. I curated three site-specific art projects with seven international RMIT student artists that extended the artists' creative practice to encompass curation and management skills. The artists were Estefanía Salas and Agustin Moreno Garcia from Spain, Tim Siteng Wei, Tin Liu, Saki Wang and Farrah Fa Zhang from China, and Enytha Buntoro from Indonesia. As a visiting curator, my goal was to activate the PS50 exhibition spaces and turn the public space of windows, streets and walls into a 'laboratory' (Bishop, 2004, p. 5I). By curating a series of monthly experimental art activities, I aimed to encourage student artists to extend their practice to develop collaborative models in the university environment.

\section{Artistic Activation}

At the beginning of this curatorial residency, the first challenge was how to initiate art exhibitions to activate the PS50 exhibition public environment and engage university communities and the public. Traditionally, visiting art galleries is a passive act of participation with defined roles for curators, artists and the public. Unlike passive white wall gallery spaces, PS50 was an opportunity for active engagement through curatorial activities that involved various partners who were engaged in the exhibition production. To set up this laboratory model, I first considered how the role of a curator could enable artists to build their power in exhibition production to use art to stimulate the vitality of the community. I propose that changing the traditional role of curators may be a way to encourage greater creativity. After working in white wall galleries for ten years, I am no longer satisfied with only curating in a dedicated art space. Instead, I craved to explore how curators can collaborate with artists in art productions itself within nonconventional public sites. In the PS50 project, I was eager to find a 'true collaboration' (Kelly, 1996, p. 139) with artists beyond the concept that 'today, curating as a profession means at least four things. It means to preserve, in the sense of safeguarding the heritage of art. It means to be the selector of new work. It means to connect to art history. Moreover, it means displaying or arranging the work' (Neuendorf, 2016). I think there is the fifth 'in-between' way to curate exhibitions. My curatorial practice considers collaborating with artists to create art, plan and produce exhibitions. My role is not limited to a curator but also a 'collaborator' among artists, creation and exhibition production.

When developing the new curatorial strategy for PS50, I used social and cultural analyses to investigate the relationship between creative practitioners, the public and creative spaces. I created an ongoing public program or action called the 'Curatorial Collaborative Laboratory' to enable emerging curators, creative practitioners and students to test new ideas and strategies to expand the public audience. As a curator who cares about the social practice and art collaboration, I rearranged the PS50 
exhibition environment, especially in the interior and exterior spaces of the windows, to develop a series of active and dynamic art practices and productions. The purpose of these actions was to help artists from different cultural backgrounds to establish collaborative relationships with artistic creation.

\section{Windowscapes}

Spatial practice is one of my primary methods for curating exhibitions. The main exhibition space of PS50 is a window view area of approximately $3 \mathrm{~m} \times 1.5 \mathrm{~m}$. How to activate this window display space between internal and external spaces or between private and public spaces was my next curatorial task. When I think of windows, it reminds me of the book 'Windowscapes' by Tokyo-based architect Yoshiharu Tsukamoto. His book explores the behaviour of discussing and analysing windows, providing ideas about the charm of windows and how windows can help create positive and negative spaces in buildings (Tsukamoto, 2010). Tsukamoto's practice inspired my curatorial strategy to explore the possibilities of 'windowscapes' inside and outside the PS50 area.

PS50's 'windowscapes' format brings a large-format feel to the street media. It provides a significant opportunity for student artists to display their works and create experimental art exhibitions in the public sphere, thereby leaving an unmissable impression on the public. 'Windowscapes' can 'create unique cultural, urban and social spaces and stimulate activities such as rest, relaxation and revival' (Tsukamoto, 20l0). After completing my first site visit to PS50, the biggest challenge I faced in this project was how to collaborate with artists through site-specific artworks. Using these 'windowscapes' to curate art exhibitions was a turning point in my curatorial practice, from guiding me to plan art exhibitions in white cube galleries to organizing art activities in public spaces. It was also a testing ground for me to understand that 'curatorial practice' is about people, not just about art exhibitions - curators, artists, space and viewers - and the dynamics between them.

Another challenge was how to activate these 'windowscapes' to curate artistic collaborations with artists on specific sites. The method of British theatre director Peter Brook motivated my curatorial practice. 'I can take any empty space and call it a bare stage. A man walks across this empty space whilst someone else is watching him, and this is all that is needed for an act of theatre to be engaged' (Brook, 1968, P. II). Brook defines 'empty space' as any space where the theatre is located. Based on the same point of view, I considered that any empty space could be an exhibition space when someone watched the artists' creation. Following this inspiration, I divided the space around PS50 into five interconnected parts, including the windows, projection walls, laneways, performance areas and co-working spaces.

\section{In-Between Collaborative Practice and Public Space}

After formulating a curatorial strategy, selecting artists for collaboration and planning the exhibition program were my next tasks. I sought out artists who were open to exploring new ways of exhibiting through collaborative practice. I designed some requirements for recruitment: artists needed to fully engage in the production process of the exhibition and participate in the PS50 artist-in-residence program for two weeks. 
The reason is that when looking back at the history of the PS50, I found that many previous exhibitions only displayed artworks behind the windows, rather than artworks that have a special connection with location and public space. The purpose of this request of participating artists was to select artists who had enough time and energy to collaborate on the exhibition site to develop and produce artworks, to explore the methods and significance of 'true collaboration'.

Conventional wisdom aside, true collaboration among artists and architects [or curators] rarely happens ... What passes today for collaboration tends in fact to be a frustrating process of compromise and concession. (Kelly, 1996, p. 139)

How can 'collaboration' be curated? This question was what I investigated during the residence. After selecting potential artists, I curated three exhibitions. Each focused on artistic collaboration and experimentation in specific locations in different ways and included installation art, performance, projection art, murals and interactive workshops. Seven student artists participated in these artistic collaborations, mainly international graduate art students, including two from Europe and five from Asia. Under this multicultural structure, artists were divided into three group exhibition projects based on their shared interests, field similarities and practical methods.

\section{'Accompanying'}

In the first project, I collaborated with two Spanish artists, Estefanía Salas and Agustin Moreno Garcia, to create an art installation and performance project titled Rip My Flesh (2017) [Fig. I.] and explored the ideas of improvisation, encounter and occurrence in the process of art production. This site-specific artwork integrated spatial and performative actions within the windows, walls and streets in and surrounding Building 50 on Orr Street, Carlton. Based on an earlier collaboration with Salas and Garcia in The Space Between Us (2017) in RMIT's First Site Gallery, we had established mutual trust in artistic collaboration. Therefore, in this PS50 project, I adopted a laissez-faire attitude. 'Collaboration is a process of mutual transformation in which the collaborators, and thus their common work, are in some way changed. Most importantly, the creative process itself is transformed in a collaborative relationship.' (Kelly, 1996, p. 140) During the art production process, I did not take the initiative to make a comment and interfere with the artists' creation. As a curator I have always been an 'accompanying person' (Liu, 20l3) to assist artists in meeting artistic needs and in addressing the on-site creation. I realized that in artistic collaboration, curators and artists must have a certain degree of trust so that everyone can freely try their own and each other's artistic concepts. Besides, this freedom of collaboration could encourage us to curate something new, which we did not know when we started to collaborate.

As exploring the expansion of artistic practice from indoor spaces (PS50 exhibition space and art studio) to the public space was one of my curatorial intentions, I considered that 'windowscapes' is an essential medium for connecting these two spaces. This is because its transparent materials allow light to pass through, and also allow the PS50 art studio to establish a visual connection with public areas. Windows are not only tools for enclosing or dividing space in pure architecture, but also provide unique opportunities for artists and me to explore the internal and external places. 
This idea appeared in the performance of Salas and Garcia, which took place on the street in front of 'windowscapes' [Figure 2]. In addition, we also projected a short art video on the wall opposite to Building 50 [Figure 3]. Through this expanded artistic practice in public space, I observed that the window is a gateway that follows the building and can be connected to another unknown world outside the building. I realized this kind of 'in-between' relationship that establishes connections between different worlds is the same as exploring unknowable creations with artists in my curatorial practice. In the process of activating the performance, I learned that the role of the curator is not only the commander of the exhibition; sometimes, the curator can be the 'accompaniment'. This investigation reminded me of what Obrist said, 'I really do think artists are the most important people on the planet, and if what I do is a utility and helps them, then that makes me happy. I want to be helpful' (Roberts, 2009).
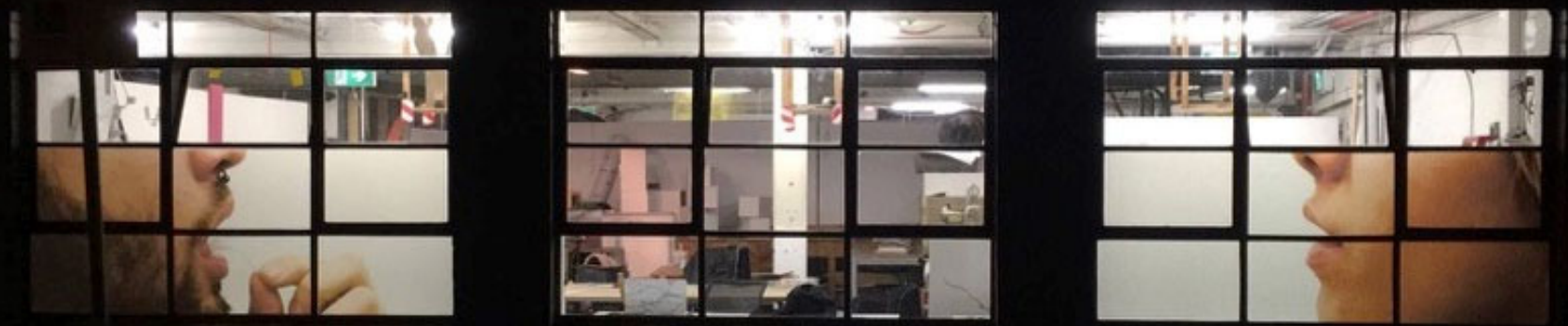

Figure I. Rip My Flesh (2017), installation art. Photo provided by the author. 


\section{In-Between Windowscapes}
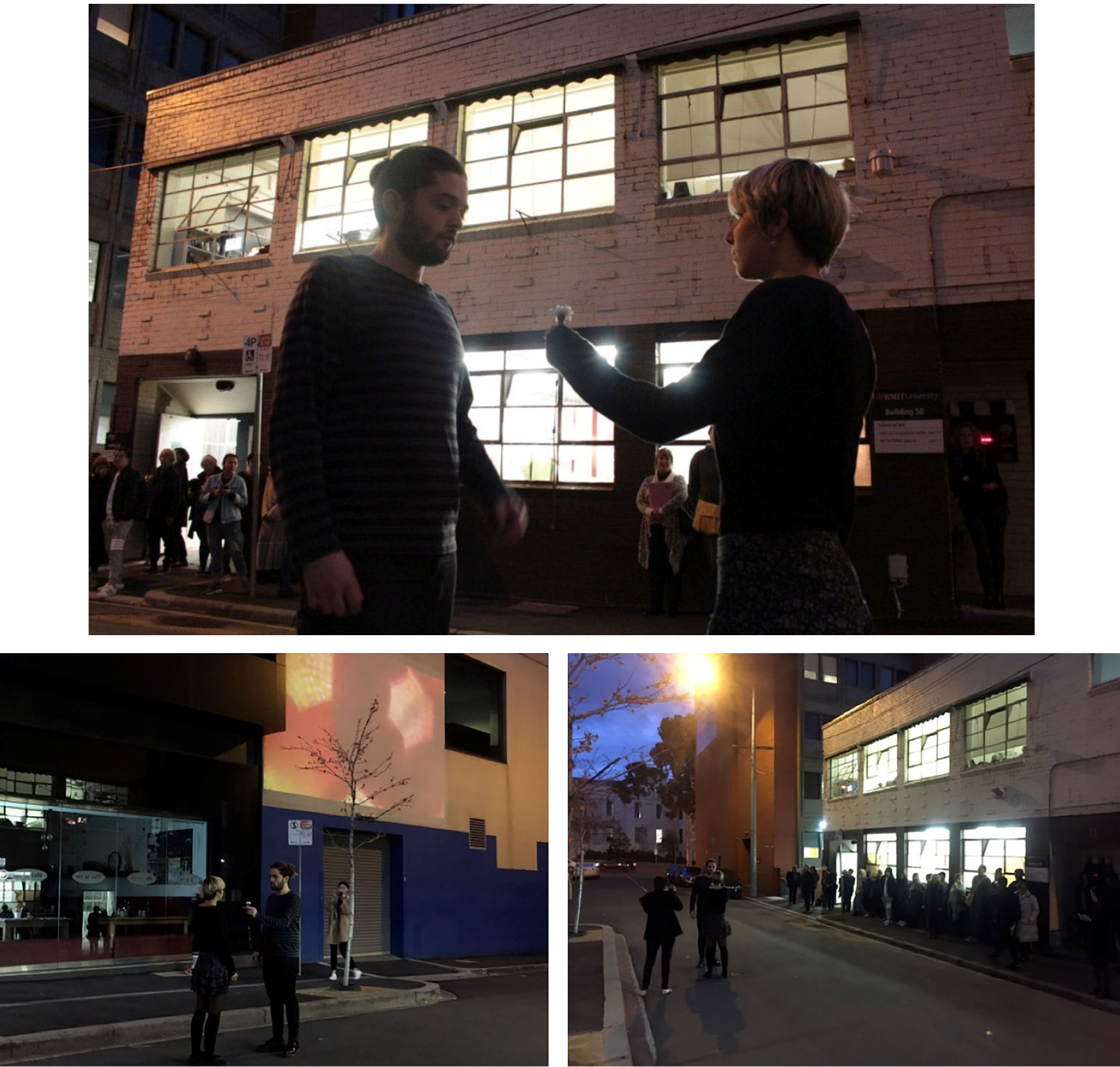

Figure 2. Rip My Flesh (2017), street performance. Photos provided by the author.

264 | The Journal of Public Space, 5(4), 2020 | ISSN 2206-9658

City Space Architecture / UN-Habitat 

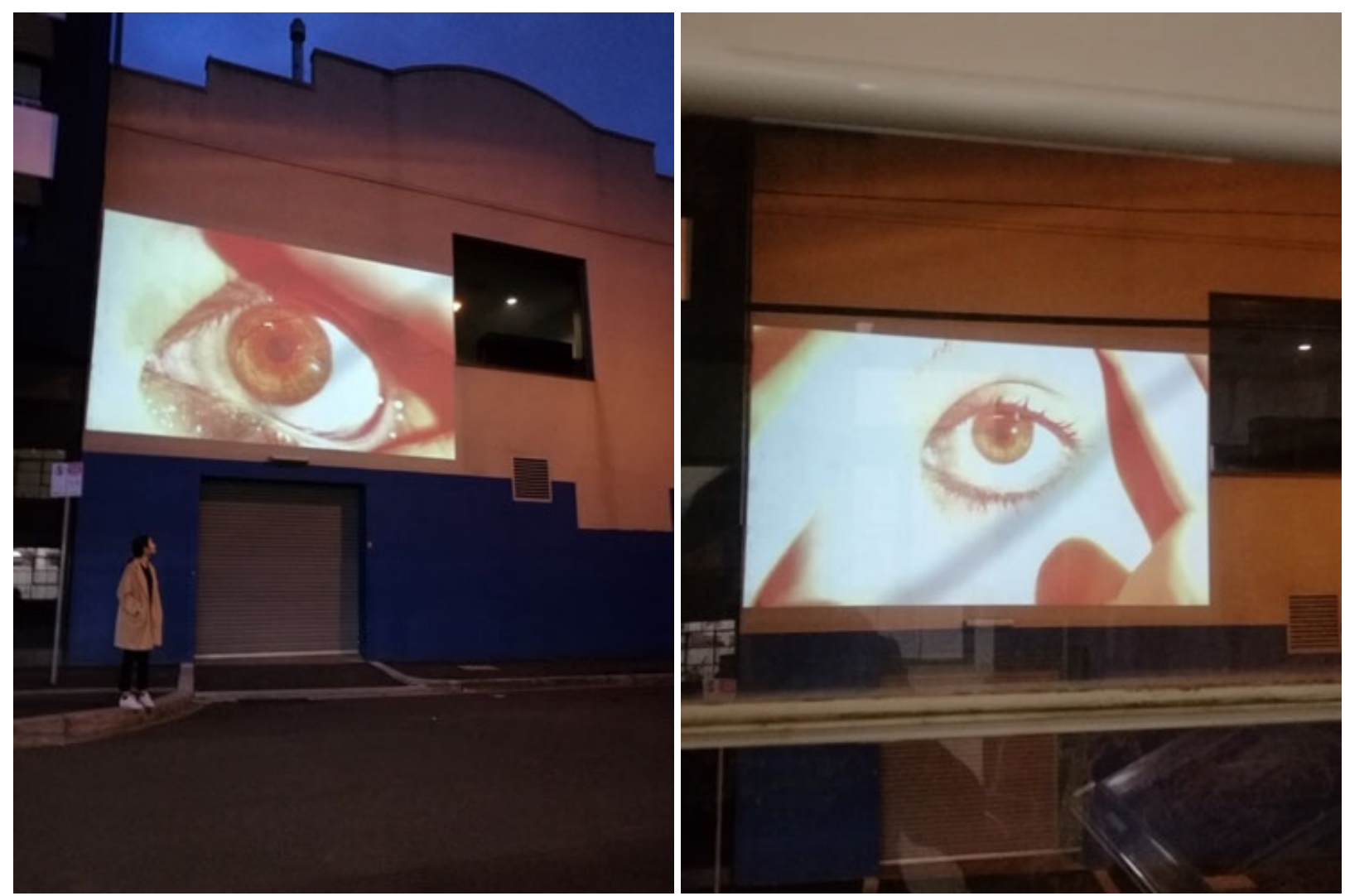

Figure 3. Rip My Flesh (2017) wall projection. Photos provided by the author.

\section{'Giving and Taking'}

In the second project, I collaborated with three Chinese artists, Siteng Wei, Tin Liu and Saki Wang, to create installation art, projection art, and performance works. Wei was dedicated to transforming Chinese landscape painting into contemporary jewellery. Tin Liu and Saki Wang focused on exploring performance art and happenings in public space. As these student artists were new in creating art installations, during the curatorial experiment, I encouraged them to explore their artistic practices through different media in the exhibition. For example, during the artist-in-residence, I worked closely with Wei and suggested he use his jewellery manufacturing technique and knowledge to create installation art on the 'windowscapes' [Figure 4]. We tested different artistic methods, such as hand-made, wax loss casting, Chinese ink painting and hand-painted drawings, to conduct experiments on acrylic plates and windows. Through these experiments, I realized the value of the exchange of professional knowledge in artistic collaboration and learned that the art of 'giving and receiving' (Garvin \& Margolis, 20I5) is one of the essential elements for establishing 'true collaboration'. 


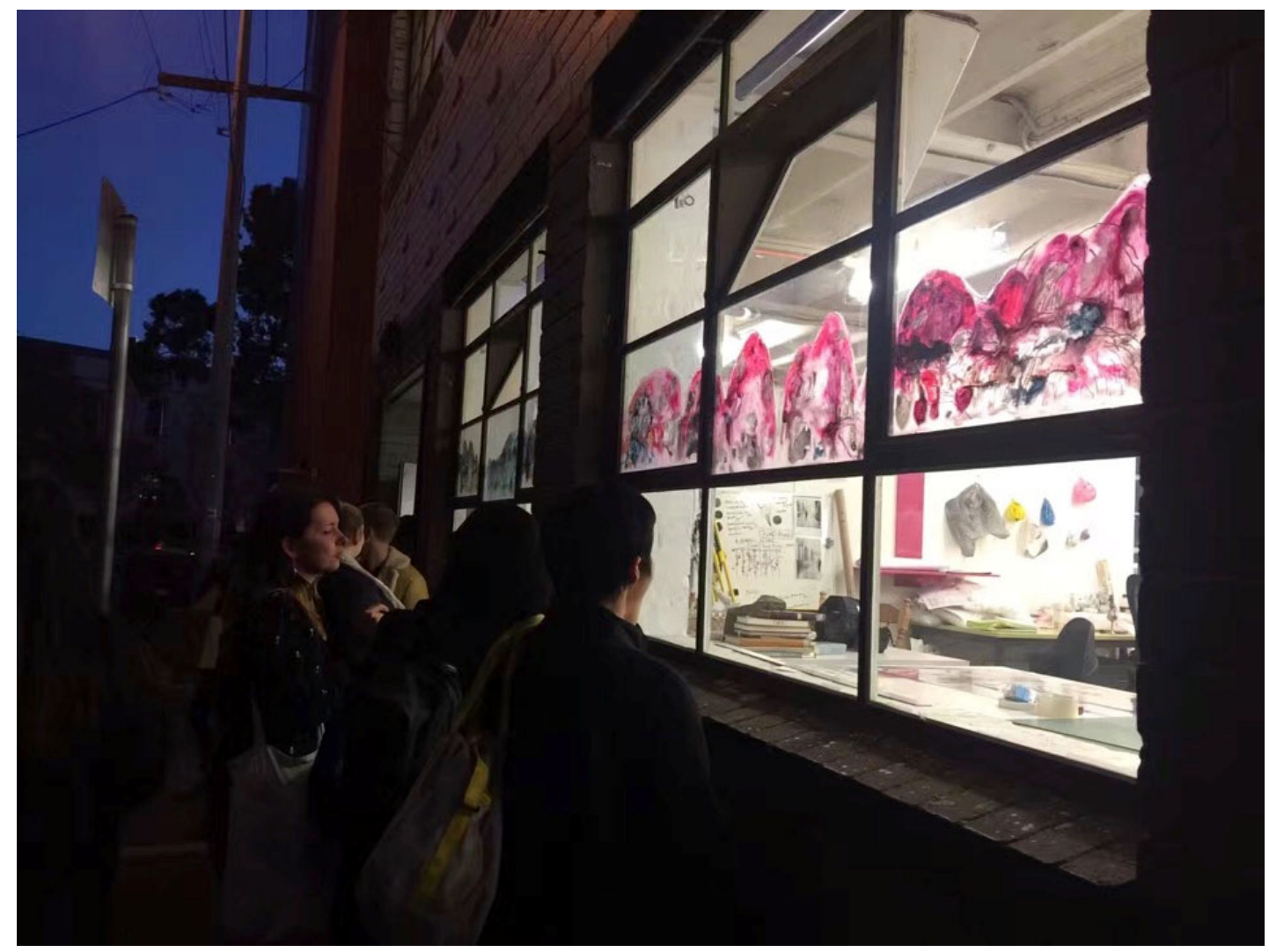

Figure 4. The public viewing Siteng Wei's landscape painting installation on the 'windowscapes' (20I7). Photo provided by the author.

The act of 'giving and receiving' reminds me of a theatre idea of 'give and take', which aims to help performers and audience to understand the idea of when to give focus and when to take focus. 'As the culture of give and take between stage and audience is established and the level of trust in the process increase, the conductor may invite a fuller story' (Chesner, 2008, p. 44). I saw that the roles of conductor and curator are the same role in creation. The idea of 'giving and taking' was very beneficial when starting creations related to our site-specific art practice. As an outcome, Wei and I set up a 3-meter-long panoramic installation art in the 'windowscapes' and linked this to a public theatrical event on the opening night of PS50 exhibition [Figure 5]. We turned the lane behind building 50 into an open-air theatre to perform Liu's Chinese shadow puppets plays and Wang's happenings [Figure 6, 7, 8, 9]. The idea of 'giving and taking' assisted me to establish a collaborative curatorial method with artists in public space through artistic activation. 


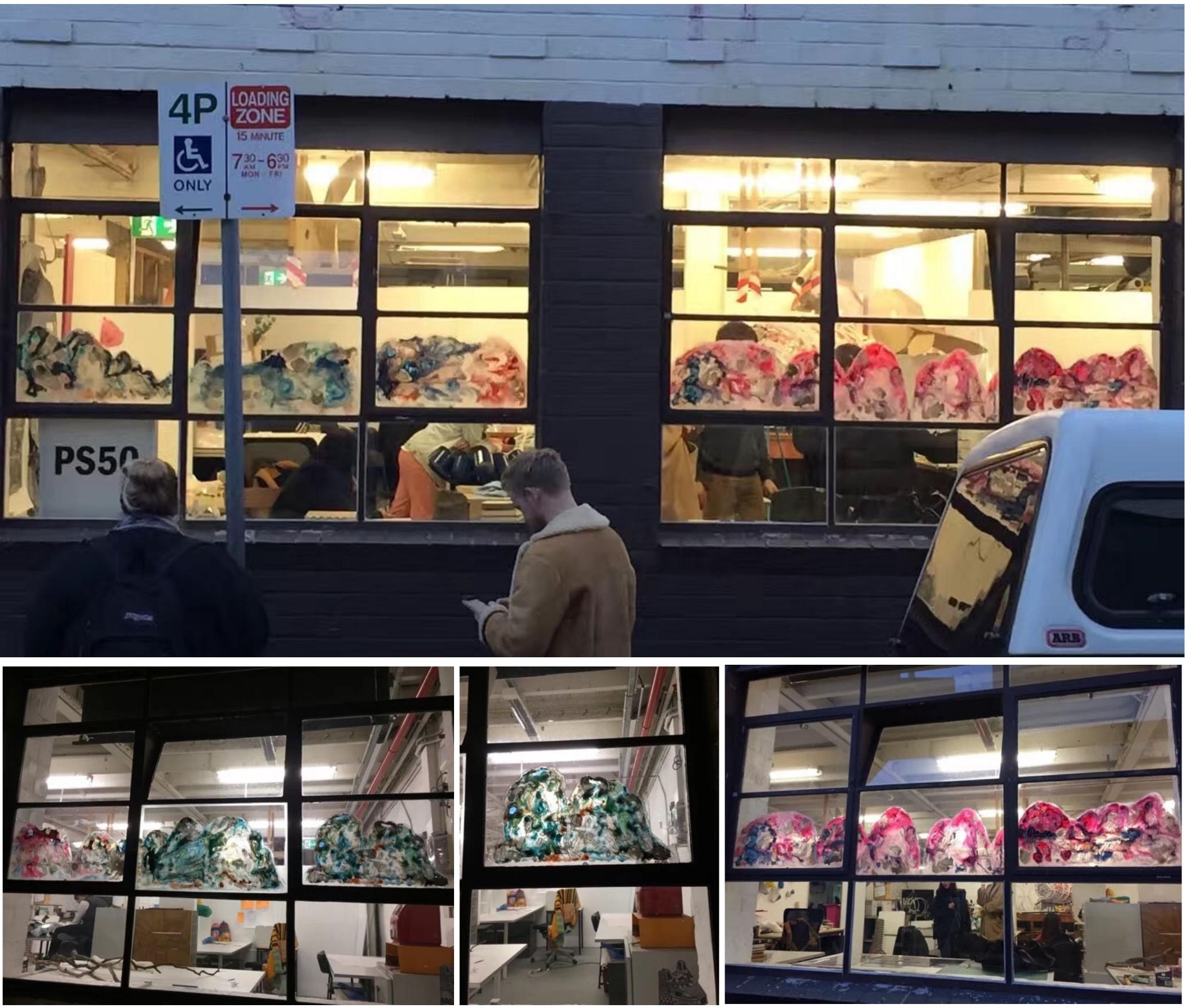

Figure 5. Different views of Siteng Wei's landscape painting installation (2017). Photos provided by the author. 


\section{In-Between Windowscapes}

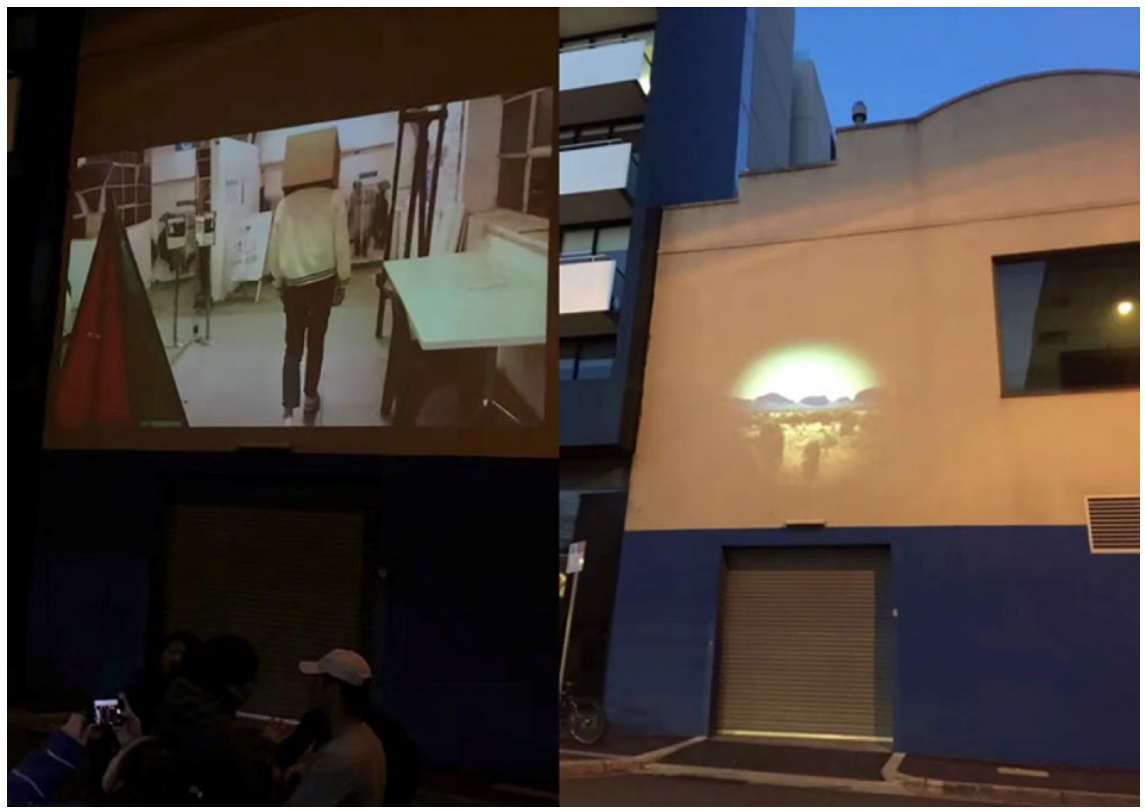

Fig. 6. Saki Wang (L) and Siteng Wei (R) projection artworks on a wall opposite to the building (2017). Photo provided by the author.
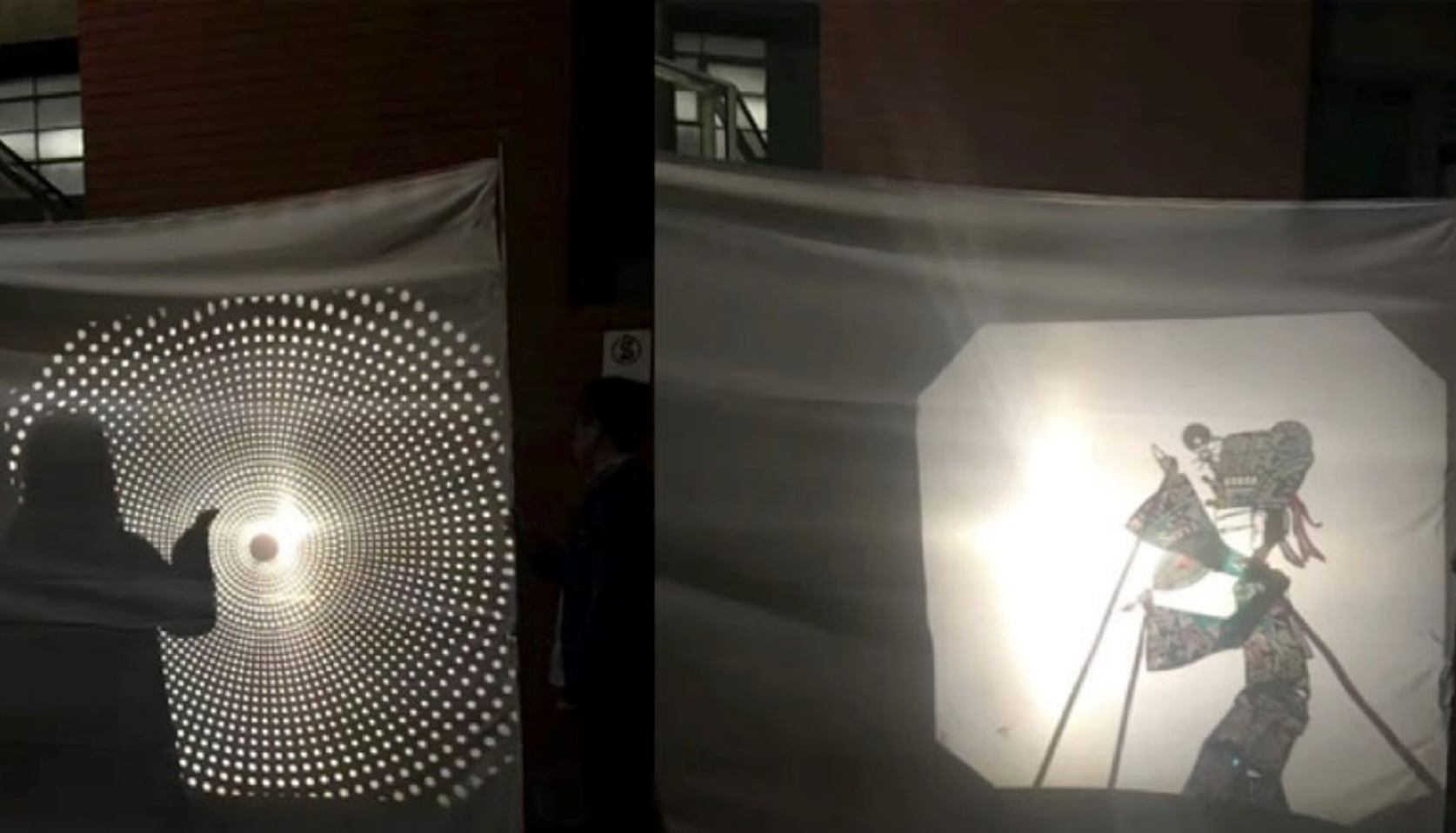

Fig. 7. Tin Liu's Chinese shadow puppets play in the laneway (2017). Photo provided by the author.

268 | The Journal of Public Space, 5(4), 2020 | ISSN 2206-9658

City Space Architecture / UN-Habitat 


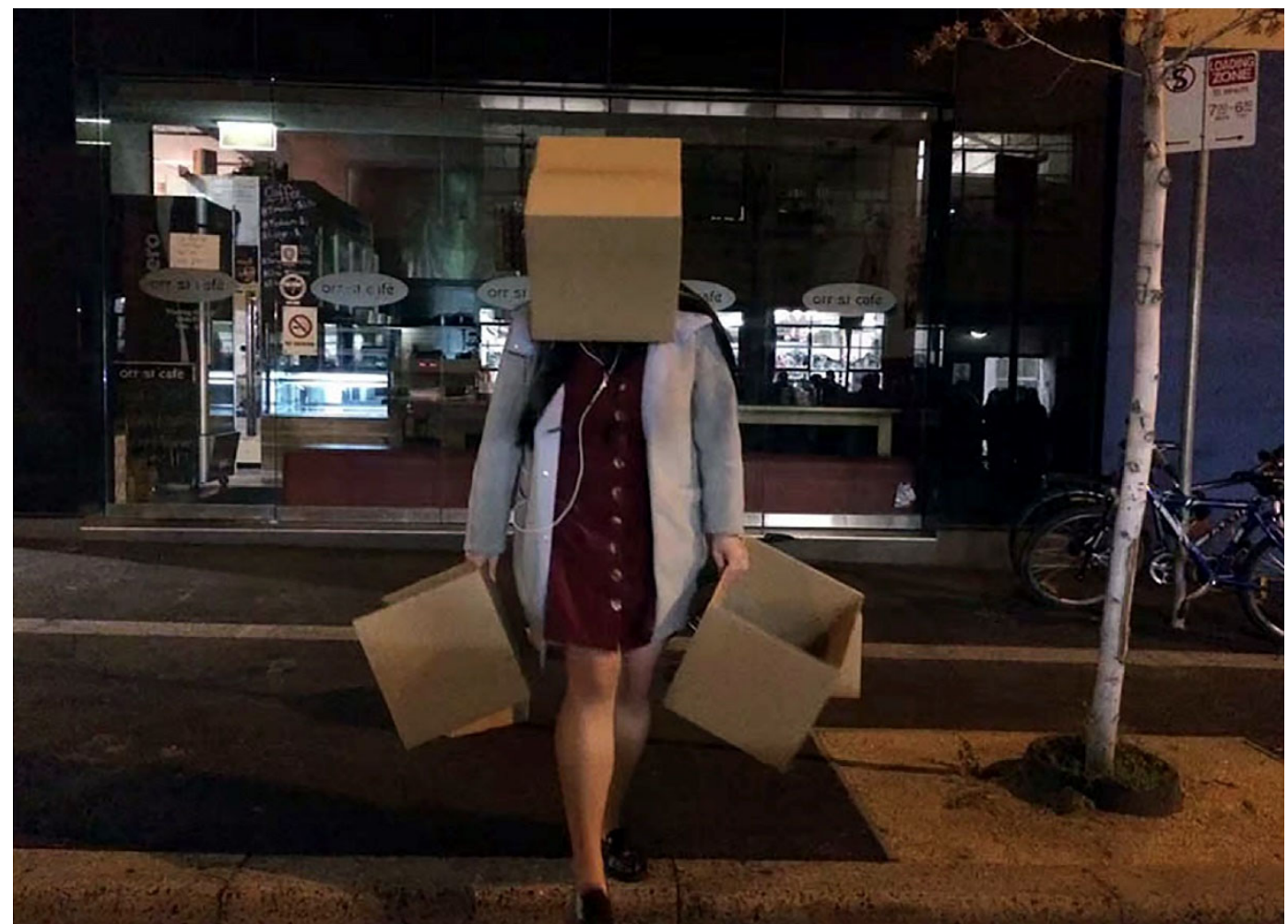

Fig. 8. Saki Wang's performance work on the street (2017). Photo provided by the author.

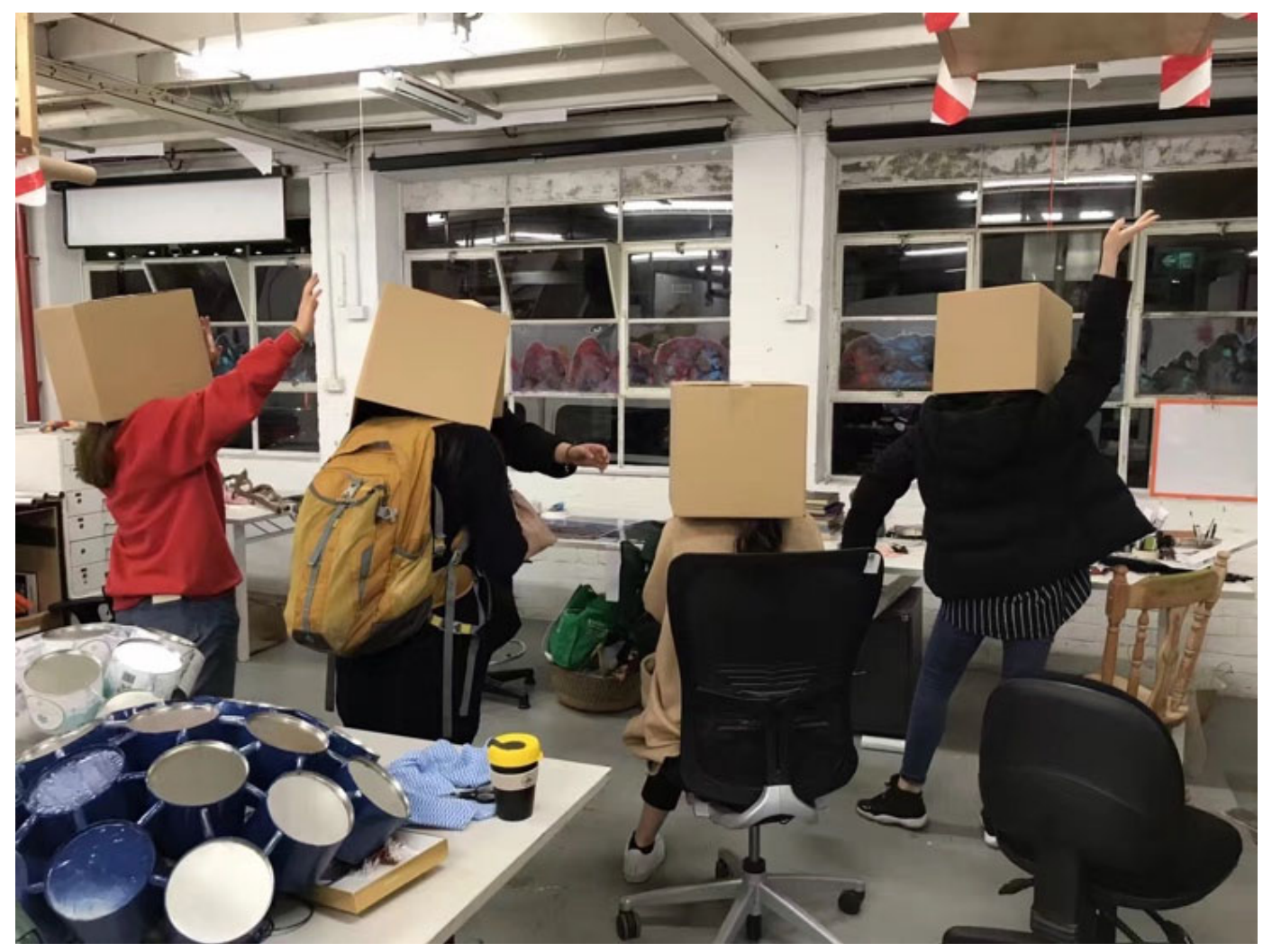

Figure 9. Saki Wang's group performance work in the PS50 studio (2017). Photo provided by the author. 


\section{'Sincere Communication'}

In the third project, I invited Fa Zhang and Enyth Buntoro, two public art graduate students from China and Indonesia, to participate in the final curatorial experiment created by openly recruited artists. Through this artistic collaboration, I understood the importance of caring for others in exhibition production. I find that curators and artists from different cultural backgrounds may have different expectations for each collaboration. Exploring everyone's expectations is a necessary process, because after clarifying everyone's needs in the production, the meaning and structure of collaboration may change. In my previous curatorial experience, I have collaborated extensively with artists, from a joint decision made by the team to projects that the artist fully controls. I am aware that if there is no sincere communication between collaborators, collaboration can sometimes be out of balance.

'Every collaboration is unique-composed of a distinctive combination of people in a specific context and is generally understood as raising fundamental questions about the nature of creative labour and the complexities of the authorial voice.

(Mabaso, 2016, p. 3)

When I collaborated with Zhang and Buntoro to create a mural on PS50's 'windowscapes' [Figure 10, II], I found that we have different ideas about the display format of the mural, which is a good thing. However, since we tried to satisfy everyone's expectations for the project and the voices of the authors, we did not truthfully express our ideas about the artwork in our collaboration. Therefore, during the production, we lost the tacit understanding and encountered many coherent misunderstandings. Communication problems are important reasons for project failure. The lack of methods to evaluate project communication performance hinders the project communication. Sometimes curators and artists have much self-awareness in creation. If the collaborators cannot communicate truthfully, it will harm the production process. These negative emotions will stifle creativity in artistic collaboration. From this experience, I realized that collaborative curatorial practice not only involves creating exhibitions but people's mutual care and sincere communication.
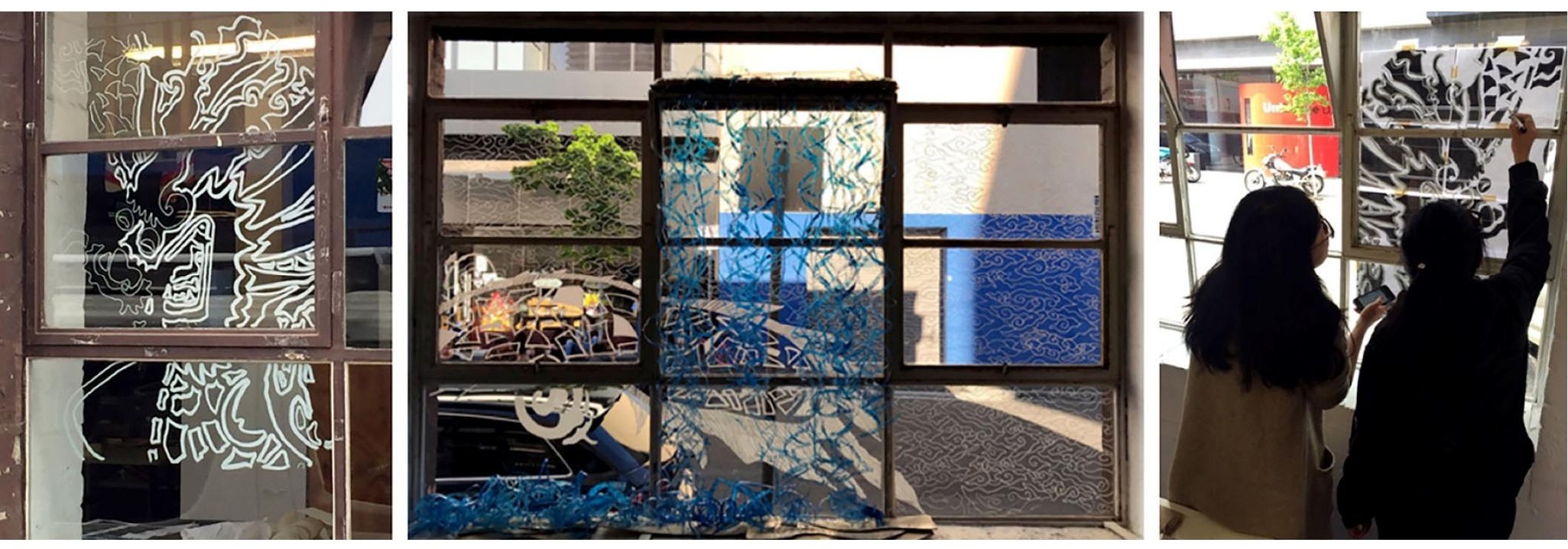

Fig. 10. The working process of Zhang and Buntoro's mural on PS50's 'windowscapes' (2017). Photos provided by the author. 


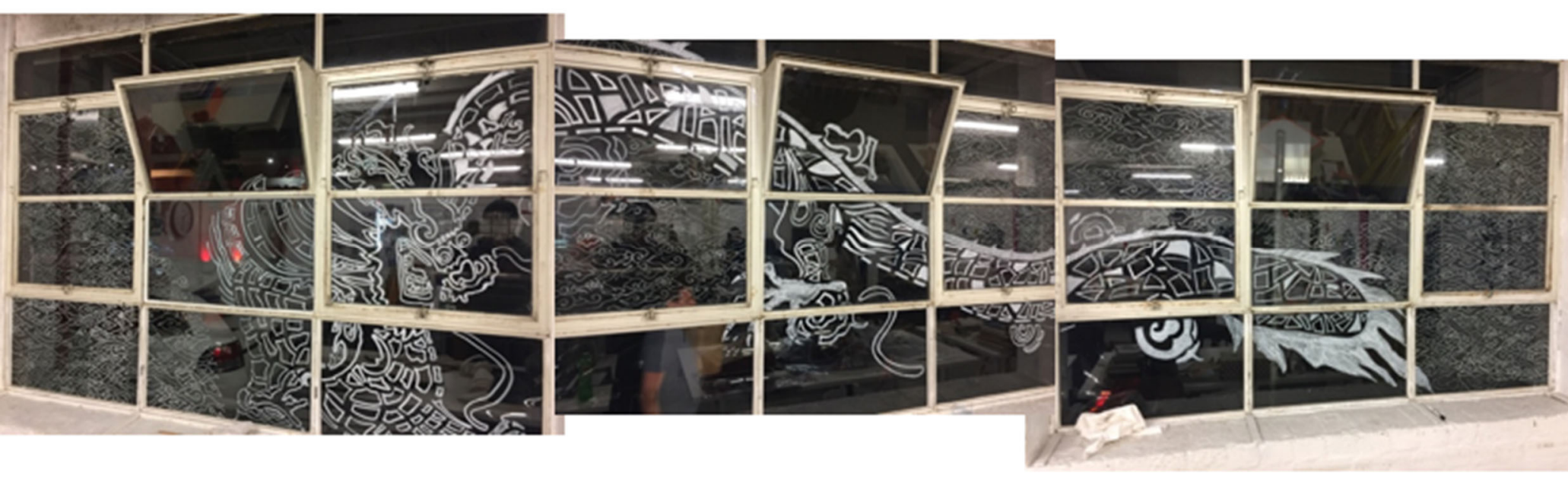

Fig. II. The final draft of Zhang and Buntoro's mural from the view of PS50 studio (2017). Photos provided by the author.

\section{Conclusion}

From the above public space art curatorial experiments, I learned that collaboration is an open concept that provides artists and curators with multiple ways to activate and produce arts in public space. Based on 'accompanying', 'giving and taking' and 'sincere communication', artists and curators can realize the mutual benefit in artistic collaboration. In most art exhibitions, curators only determine the background, framework and content of the exhibition, while the artists usually lead the process and development of artistic creation. Therefore, it is worth exploring how to make the curators and artists carry out 'true collaboration' further in actual exhibition production processes. The role of the curator can be turned into a 'collaborator' so that collaborative methods in public space can be adopted to activate the organicity of artistic creation. Following this residency program, in early 2018 , several students and I co-founded a student-led initiative named RMIT Curatorial Collective (RCC), which aims to provide student artists with opportunities to collaborate with interdisciplinary creative practitioners and the public, from art and social theories to curatorial practices. 


\section{References}

Bishop, C. (2004). Antagonism and Relational Aesthetics. City University of New York. Retrieved from https://academicworks.cuny.edu/cgi/viewcontent.cgi?article $=1095 \&$ con text $=$ gc

Chesner, A. \& Hahn, H. (2002). Creative Advances in Groupwork. London: Jessica Kingsley Publishers.

Garvin, D.A. \& Margolis, J.D. (20I5). The Art of Giving and Receiving Advice. Harvard Business Review, From the January-February 2015 Issue. Retrieved from

https://hbr.org/2015/0I/the-art-of-giving-and-receiving-advice

Kelly, J. ( 1996). 'Common work' in Lacy, S.(ed.) MAPPING THE TERRAIN New Genre Public Art. Toronto: Bay Press, pp. 139-148.

Ding, L. (20I3). 'Artist as Curator: Collaborative Practices' Symposium: 'I Simply Appear in the Company of.... Afterall. Retrieved from https://www.afterall.org/online/_artist-ascurator_collaborative-practices_symposium_i-simply-appear-in-the-companyof... \#.XzSRvpMzamk

Mabaso, N. (2016). In this Context: Collaborations \& Biennials, Oncurating, Issue 32/October. Retrieved from https://www.on-curating.org/issue-32-reader/in-this-context-collaborationsbiennials.htm|\#.XzRi65Mzamk

Neuendorf, H. (2016, November 10). Art Demystified: What Do Curators Actually Do? Artnetnews. Retrieved from https://news.artnet.com/art-world/art-demystified-curators$\underline{741806}$

RMIT Curatorial Collective. (2020). RMIT Curatorial Collective. Retrieved from https://rcccuratorial.wixsite.com/home

Roberts, A. (2009, October 22). 'Hans Ulrich Obrist - The God of Planet Art'. The London Evening Standard. Retrieved from https://www.standard.co.uk/arts/hans-ulrich-obrist-thegod-of-planet-art-6741077.html

Tsukamoto, Y. (2010). WINDOWSCAPE. Japan: Flim Art, Inc. 